Universidade de São Paulo

Escola Superior de Agricultura "Luiz de Queiroz"

Estudos genéticos em uma população segregante de maracujá-doce selecionada para qualidade de frutos

Lourdes Maria Chavarría Pérez

Tese apresentada para obtenção do título de Doutora em

Ciências. Área de concentração: Genética e Melhoramento de Plantas

Piracicaba 
Lourdes Maria Chavarría Pérez

Engenheira Agrônoma

Estudos genéticos em uma população segregante de maracujá-doce selecionada para qualidade de frutos

Orientadora:

Profa. Dra. MARIA LUCIA CARNEIRO VIEIRA

Tese apresentada para obtenção do título de Doutora em Ciências. Área de concentração: Genética e Melhoramento de Plantas

\section{Piracicaba}

2017 
RESUMO

\title{
Estudos genéticos em uma população segregante de maracujá-doce selecionada para
}

\section{qualidade de frutos}

\begin{abstract}
As frutíferas nativas do Brasil são subexploradas comercialmente, sendo que os programas de melhoramento genético são bastante incipientes, devido a muitas limitações associadas à fisiologia e biologia dessas espécies, embora apresentem potencial econômico tanto para o consumo in natura como para o processamento industrial. No Brasil, o maracujá-doce (Passiflora alata) está conquistando novos clientes e mercados, e tem atingido preços até três vezes maiores do que os do maracujá-azedo, amplamente cultivado no país. Os frutos do maracujá-doce são muito apreciados, embora apenas a seleção empírica tenha sido praticada. Evidentemente, seria muito vantajoso obter uma variedade geneticamente superior em termos de qualidade e produção de frutos. Nesse sentido, nosso grupo de pesquisa tem focado esforços visando a caracterizar geneticamente uma população segregante de maracujá-doce. Aqui, foram avaliados 30 genótipos desta população, previamente selecionados como superiores. Estes foram plantados sob três condições experimentais: Anhumas (2014/2015 e 2015/2016) e Piracicaba (2015/2016). Foi utilizado o delineamento em blocos casualizados, sendo que as análises genético-estatísticas tiveram por base a abordagem de modelos mistos para a predição dos valores genéticos (BLUPS). Foram estimados parâmetros genéticos e fenotípicos, herdabilidade, correlações genéticas e resposta esperada à seleção relativamente a peso $(\mathrm{PF})$, comprimento $(\mathrm{CF})$ diâmetro $(\mathrm{DF})$ do fruto, espessura (EC) e peso (PC) da casca, peso (PP) e rendimento de polpa (RP), teor de sólidos solúveis totais (SST) e Produtividade. Os resultados mostraram haver altas correlações genéticas entre os principais atributos do fruto, assim como valores elevados de herdabilidade (desde 0,45 para PF a 0,94 para EC), valores que favorecem a prática de seleção. Em seguida, foi aplicado índice multiplicativo para fins de seleção e seis genótipos foram indicados como superiores, quais sejam: 49, $21,107,125,140$ e 122. Nossos resultados devem auxiliar outros estudos e iniciativas de seleção de genótipos mais produtivos, evidenciando a grande utilidade de ferramentas estatísticas modernas para se obter maior resposta à seleção. Em paralelo, foi estudada a resposta do maracujá-doce à infecção causada por Xanthomonas axonopodis. Dois genes, previamente identificados como superexpressos no maracujá-azedo, e que codificam as enzimas lipoxigenase-2 e (+)-neomentol desidrogenase foram aqui analisados via qPCR. No maracujá-doce observou-se maior expressão da (+)-neomentol desidrogenase, enzima associada à resposta de hipersensibilidade. Os sintomas da doença sugerem que a resposta de hipersensibilidade é particular no maracujá-doce, já que ocorre a queda precoce das folhas, evitando a disseminação sistêmica da bactéria.
\end{abstract}

Palavras-chave: Passiflora alata; População segregante; Modelos mistos; BLUPS; Correlação genética; Heredabilidade; Índice de seleção multiplicativo; Xanthomonas axonopodis;

Lipoxigenase 2; (+)-neomentol desidrogenase 


\title{
ABSTRACT
}

\section{Genetic studies in a segregant population of sweet passion fruit selected for fruit quality}

\begin{abstract}
Brazilian native fruit species are under-exploited commercially, and breeding programs are quite incipient due to many limitations associated with the physiology and biology of these species, although having economic potential both for in natura consumption as well as for industrial processing. In Brazil, the sweet passion fruit (Passiflora alata) is conquering new customers and markets, and has riched up to triple the sour passion fruit prices, widely grown in the country. The fruits of the sweet passion fruit are much appreciated, although only empirical selections have been practiced. Evidently, it would be very beneficial to obtain a genetically superior variety in terms of fruit quality and production. In this scenario, our research group has focused efforts to genetically characterize a segregating population of sweet passion fruit. Here, we evaluated 30 genotypes previously selected from this population by field-cultivating them under three experimental conditions: Anhumas (2014/2015 and 2015/2016) and Piracicaba (2015/2016). A randomized block design was used, and the genetic-statistical analyzes were based on a mixed-effects model approach in order to predict the genetic values (BLUPS). We estimated genetic and phenotypic parameters, as heritability, genetic correlations and expected response to selection for weight (WF), length (LF) diameter (DF) of the fruit, thickness (TS) and weight (WS) of the shell, weight (WP) and pulp yield (PY), total soluble solids (SS) and fruit yield. We found high genetic correlations between the main fruit attributes, as well as high values of heritability (from 0.45 for WF up to 0.94 for TS), values that may favor selection practices. Then, we applied a multiplicative selection index and six superior genotypes were selected, which are: 49, 21, 107, 125, 140 and 122. Our results may assist other studies and initiatives of selection of more productive genotypes, showing the great usefulness of modern statistical tools to obtain greater responses to selection. In parallel, we studied the response of sweet passion fruit to infection caused by Xanthomonas axonopodis. Two genes, previously identified as overexpressed in sour passion fruit, and that encode the enzymes lipoxygenase-2 and $(+)$-neomentol dehydrogenase were herein analyzed via qPCR. In the sweet passion fruit an increased expression of $(+)-$ neomentol dehydrogenase, an enzyme associated with hypersensitivity response, was observed. The disease symptoms suggest that the response of hypersensitivity is particular in sweet passion fruit, since it provokes the premature fall of the leaves, thereby preventing the systemic bacterial dissemination.
\end{abstract}

Keywords: Passiflora alata; Segregating population; Mixed models; BLUPS; Genetic correlation; Heritability; Multiplicative index selection; Xanthomonas axonopodis multiplicative; Lipoxygenase 2; (+)neomenthol dehydrogenase 


\section{INTRODUÇÃO}

Recentemente, a Organização das Nações Unidas para Agricultura e Alimentação (FAO) previu que a população mundial deve superar os oito bilhões até o ano 2030 (FAO, 2015). Portanto, a demanda por alimentos aumentará drasticamente. Conforme consta do relatório da FAO, "Agricultura para 2015/30", realizaram-se progressos notáveis nas últimas três décadas para alimentar a população mundial. Mesmo assim, a produção de alimentos deverá ser $70 \%$ maior em 2030 relativamente ao que se produz atualmente para suprir a necessidade mundial. Frutas e vegetais terão um papel importante no fornecimento de vitaminas essenciais, minerais e fibras alimentares, tanto em países desenvolvidos como em desenvolvimento.

O levantamento da Confederação da Agricultura e Pecuária do Brasil (CNA, 2017) sobre o consumo de frutas e hortaliças mostrou que apenas 18,2\% dos brasileiros ingerem a quantidade de frutas recomendada pela Organização Mundial da Saúde (OMS). Este estudo também mostrou que os brasileiros gastam, em média, apenas $6,2 \%$ de sua renda na aquisição de frutas e hortaliças, embora o país seja o terceiro maior produtor de frutas do mundo, atrás somente da China e da Índia (CNA 2017a, b). Isso motiva as principais instituições de pesquisa agrícola a se envolverem com pesquisas que levem ao aumento da produção e, assim promover uma redução de custo e permitir o maior acesso a este tipo de alimento por parte da população brasileira.

A importância e os objetivos dos programas de melhoramento de fruteiras variam de acordo com a espécie e o ambiente. As principais tendências são (i) o desenvolvimento de cultivares que simplifiquem as práticas nos pomares, diminuindo assim os custos de produção, (ii) o aumento da resistência a estresses bióticos e abióticos, (iii) a ampliação das zonas de adaptação das culturas frutíferas e (iv) a melhoria da qualidade dos frutos. Neste contexto, programas de melhoramento genético são fundamentais para o estabelecimento de pomares mais produtivos e os modelos genético-estatísticos adotados devem ser capazes de predizer adequadamente as respostas à seleção (Viana \& Resende 2014).

Os maracujazeiros (Passiflora spp.) têm um papel importante na fruticultura nacional, já que constituem uma fonte adicional de renda ao pequeno produtor. O gênero Passiflora (Passifloraceae) é originário da América tropical e subtropical, sendo a maioria das espécies encontrada no Brasil, e 80 são consideradas endêmicas (Bernacci et al. 2015). Apenas duas espécies são exploradas comercialmente, o maracujá-azedo ( $P$. edulis) e o doce ( $P$. alata). O país 
é considerado o principal produtor e consumidor, havendo muitas áreas com vocação para a cultura do maracujá, além das boas condições de solo e clima necessárias para o seu desenvolvimento em diversos estados (CNA 2017a). No ano de 2013, foram cultivados 58.089 hectares, com uma produção de 923.035 toneladas de frutos, sendo que a grande maioria da produção (quase 80\%) foi destinada à indústria de suco concentrado e o restante consumido como fruta de mesa (IBGE, 2015).

O maracujá-azedo ocupa a grande maioria dos pomares comerciais, porém o maracujádoce tem alcançado o triplo do valor do azedo nos mercados. Segundo Bernacci et al. (2003) este é um dos principais motivos da expansão dos plantios de maracujá-doce. O sabor exótico dos frutos é atrativo para o consumo humano, seja in natura, seja na forma de produtos processados e devido ao seu alto valor comercial é desejável cultivá-lo em maior escala.

Apesar do potencial para ser explorada como fruta tropical, são raros os estudos genéticos dirigidos para melhorar a cultura maracujá-doce. Não há programas de melhoramento em andamento no país, já que os custos são altos para o estabelecimento de populações em condições de campo, além de existir pouco conhecimento sobre os tratos culturais gerais para o desenvolvimento dos pomares. Esse pouco conhecimento e a indisponibilidade de material selecionado são traduzidos para o agricultor como um investimento de risco. Além dos custos de estabelecimento da lavoura, a carência de variedades melhoradas é responsável pela evidente variabilidade dentro dos pomares, tanto em produtividade quanto em qualidade dos frutos.

Nesse cenário, nosso grupo de pesquisa tem direcionado esforços para conhecer melhor a cultura e realizar estudos que possam levar ao desenvolvimento de cultivares e consequentemente propiciar a expansão do seu cultivo no país. Assim, a partir do cruzamento de dois acessos distintos, designados SV3 (genitor masculino) e 2(12) (genitor feminino), foi obtida uma progênie segregante $\left(F_{1}\right)$ que tem sido empregada como população de estudo (Nunes 2010; Laperuta 2011). O acesso SV3 é uma "variedade-local", cultivada em uma área de produção na região de Piracicaba, SP. O acesso 2(12) foi cedido à ESALQ pela Embrapa Cerrados e é um dos membros de uma progênie cuja planta mãe foi coletada na região Amazônica (Ferreira et al. 2010).

A população $F_{1}$, constituída por 180 indivíduos, irmãos-germanos, foi usada para a construção do primeiro mapa genético da espécie (Pereira et al. 2013); paralelamente, 100 indivíduos desta população foram analisados quanto à produção e qualidade de frutos, em plantios realizados em dois locais do Estado de São Paulo e durante dois anos consecutivos 
(Nunes 2010; Laperuta 2011). Em ambos os experimentos, foi adotado o delineamento em látice quadrado 10 x 10 com duas repetições por local. Os dados fenotípicos foram analisados comparativamente em relação às médias dos dois locais e dos dois anos de produção. A partir dessas análises foi constatada ampla variabilidade genética entre os indivíduos, a qual pode ser explorada visando à seleção de clones superiores.

A partir desses dados, foram realizadas análises genético-estatísticas para a estimação de parâmetros de interesse genético e também procedeu-se ao mapeamento de locos quantitativos (QTLs) associados com o controle de caracteres associados à qualidade dos frutos (Pereira et al. 2016).

Para as análises fenotípicas foi empregada a abordagem de modelos mistos para a estimação dos principais parâmetros, enquanto para o mapeamento de locos quantitativos foi empregada a metodologia de mapeamento por intervalo composto (CIM). Com base nas magnitudes das correlações genéticas observadas para os caracteres relacionados à qualidade do fruto, entre eles, espessura da casca, peso do fruto e peso de polpa, foi estabelecido um índice de seleção multiplicativo. Com isso, foi possível selecionar 30 genótipos superiores para os seguintes caracteres, diminuição de peso e da espessura da casca e aumento do conteúdo de polpa, levando-se em conta as correlações entre os caracteres. Esta subamostra constituiu o material biológico analisado no presente trabalho, cujo objetivo foi proceder a uma nova avaliação, sob três condições experimentais, no que tange à qualidade dos frutos e à produtividade.

Em paralelo, foi possível caracterizar o comportamento de oito genótipos, dentro destes 30 selecionados para a qualidade de fruto, quanto a resposta à infeção por Xanthomonas axonopodis pv. passiflorae, agente causador da mancha bacteriana, uma doença de difícil controle químico. Esta doença causa perdas extensivas nos plantios, atingindo, em alguns casos, perdas de até 100\% do pomar (Bellon et al. 2007).

Desse modo, o objetivo desta pesquisa foi analisar a população segregante de maracujádoce selecionada para a qualidade de fruto, incluindo estimativas de componentes de variância genética, correlações genéticas entre os caracteres, presença de interação do tipo G x E, com o intuito de selecionar os genótipos indicados como superiores para a qualidade e produção de frutos. E ao mesmo, tempo analisar o comportamento da resposta à bacteriose já que há poucas informações e iniciativas referentes ao melhoramento. 


\subsection{Considerações finais}

O Brasil não dispõe de materiais geneticamente melhorados de várias epécies frutíferas nativas, incluindo o maracujá-doce (Passiflora alata). As tentativas de melhoria são escassas e incipientes, e os materiais plantados são oriundos de seleção empírica.

O uso de ferramentas da genética quantitativa para a estimação de parâmetros fenotípicos e genotípicos, a partir de dados analisados pela abordagem de modelos mistos, via REML/BLUP, permitiu a análise de um conjunto de dados, mesmo desbalanceados, o qual é de grande importancia uma vez que o desbalanceamento foi inevitável devido à natureza dos diferentes genótipos de maracujazeiro-doce, com diferentes respostas de adaptabilidade a situações de plantio e experimentais.

A população aqui estudada foi constituída de 30 irmãos-germanos e, apesar deste pequeno número, diferenças significativas entre os genótipos foram observadas para os diferentes caracteres. Observou-se forte correlação entre os caracteres relativos aos atributos dos frutos, quais sejam: PF, DF, EC, PC e PP. Sugere-se que é possível obter uma resposta à seleção favorável para os caracteres de interesse, gradualmente, mesmo que estes sejam inversamente correlacionados. Sugere-se também que mediante o uso de índices de seleção (IM) é possível obter maiores ganhos de seleção do que se realizada a seleção direta para cada caráter. Seis genótipos foram classificados como superiores tanto em qualidade de frutos como em produtividade. Após avaliar a compatibilidade entre eles, estes poderão ser disponibilizados para plantio, ou usados como genitores em dialelos completos e as progenies reavaliadas visando conduzir um novo ciclo de seleção.

Em vista da importância de avaliar a resposta em seis genótipos da progênie aqui estudada à infeção por Xanthomonas axonopodis, foi comparada a expressão dos genes que codificam as enzimas lipoxigenase-2 e (+)-neomentol desidrogenase, ambas implicadas na resposta de defesa do maracujá-azedo. No maracujá-doce observou-se maior expressão diferencial da $(+)$-neomentol desidrogenase. Os sintomas da doença sugerem que a resposta de hipersensibilidade nas espécies é distinta, provocando no maracujá-azedo uma forte lesão necrótica enquanto no doce, ocorre a queda precoce das folhas, evitando a disseminação sistêmica da bactéria. 


\section{Referências}

AGRIANUAL. Anuário da agricultura brasileira. 21 edição, p. 497, 2016.

AKAIKE, H. A New Look at the Statistical Model Identification. IEEE Transactions on Automatic Control, v. 19, n. 6, p. 716-723, 1974.

BERNACCI, L.; CERVI, A. C.; MILWARD-DE-AZEVEDO, M. A.; NUNES, T. S.; IMIG, D. C.; MEZZONATO, A. C. Passifloraceae in Lista de Espécies da Flora do Brasil. Jardim Botânico do Rio de Janeiro. Growing knowledge: an overview of Seed Plant diversity in Brazil, v. 66, n. 4, p. 1085-1113, 2015. Disponível em: $<$ http://floradobrasil.jbrj.gov.br/jabot/floradobrasil/FB12506>.

BERNARDO, R. Breeding for quantitative traits in plants. 2nd. ed. Woodbury, Minnesota, USA.: Stemma Press, 390 p, 2010.

BRITO, S. G. D. E. Auto-Incompatibilidade no Maracujazeiro Amarelo. 2010. 21 p. Tese (Doutor em Agronômia). UNIVERSIDADE FEDERAL RURAL DE PERNAMBUCO, 2010.

BUTLER, D.; CUllis, B.; GILMOUR, A.; GOGEL, B. Analysis of Mixed Models for Slanguage Environments: ASReml-R Reference Manual. Queensland Government, n. March, 2009.2 Disponível em: $<$ http://scholar.google.com/scholar?hl=en\&btnG=Search\&q=intitle:mixed + models + for $+\mathrm{S}+$ language + environments $+\mathrm{ASR}$-ml $-\mathrm{R}+$ reference + manual $\# 0>$.

CARVALHO, C.; KIST, B. B.; SANTOS, C. E.; FILTER, M. T. e C. F. Anuário Brasileiro da Fruticultura Brazilian Fruit Yearbook. Editora Gazeta, p. 88, 2017.

CAVAlCANTE, N. R.; KRAUSE, W.; VIANA, A. P.; SIlVA, C. A.; PORTO, K. K. X.; MARTINEZ, R. A. S. Anticipated selection for intrapopulation breeding of passion fruit. Acta Scientiarum. Agronomy, v. 39, n. 2, p. 143, 2017. Disponível em: <http://periodicos.uem.br/ojs/index.php/ActaSciAgron/article/view/31022>.

CNA. Balanço 2016/Perpectivas 2017. Fruticultura CNA, p. 93-97, 2017.

COBB, J. N.; DECLERCK, G.; GREENBERG, A.; CLARK, R.; MCCOUCH, S. Nextgeneration phenotyping: Requirements and strategies for enhancing our understanding of genotype-phenotype relationships and its relevance to crop improvement. Theoretical and Applied Genetics, v. 126, n. 4, p. 867-887, 2013. 
CULLIS, B. R.; SMITH, A. B.; COOMBES, N. E. On the design of early generation variety trials with correlated data. Journal of Agricultural, Biological, and Environmental Statistics, v. 11, n. 4, p. 381-393, 2006.

ELSTON, A. R. C. A Weight-Free Index for the Purpose of Ranking or Selection with Respect to Several Traits at a Time. International Biometric Society, v. 19, n. 1, p. 85-97, 1963.

FALEIRO, F. G. .; JUNQUEIRA, N. T. V. .; BRAGA, M. F. Germoplasma e melhoramento genético do maracujazeiro - desafios da pesquisa. In: Maracujá: germoplasma e melhoramento genético. $1^{\mathrm{a}}$ ed. Planaltina, DF.: Embrapa Cerrados, 2005. p. 187-210.

FERRÃO, R. G.; FONSECA, A. F.; FERRÃO, M. A. G.; FILHO, A. C. V.; VOLPI, P. S.; MUNER, L. H. De; LANI, J. A.; PREZOTTI, L. C.; VENTURA, J. A.; MARTINS, D. dos S.; MAURI, A. L.; MARQUES, E. M. G. F. Z. Café conilon técnicas de produção com variedades melhoradas. Instituto Capixaba de Pesquisa, Assistência Técnica e Extensão Rural, p. 74, 2012.

FIGUEIREDO, A. G.; VON PINHO, R. G.; SILVA, H. D.; BALESTRE, M. Application of mixed models for evaluating stability and adaptability of maize using unbalanced data. Euphytica, v. 202, n. 3, p. 393-409, 2015.

FRITSCHE-NETO, R.; BORÉM, A. Fenômica: como fenotipagem de próxima geração está revolucionando o melhoramento de plantas. Viçosa, MG: Ed. UFV, 2016.

HEFFNER, E. L.; LORENZ, A. J.; JANNINK, J. L.; SORRELLS, M. E. Plant breeding with Genomic selection: Gain per unit time and cost. Crop Science, v. 50, n. 5, p. 1681-1690, 2010.

HEFFNER, E. L.; SORRELLS, M. E.; JANNINK, J. L. Genomic selection for crop improvement. Crop Science, v. 49, n. 1, p. 1-12, 2009.

JANNINK, J.-L.; LORENZ, A. J.; IWATA, H. Genomic selection in plant breeding: from theory to practice. Briefings in Functional Genomics, v. 9, n. 2, p. 166-177, 2010. Disponível em: <https://academic.oup.com/bfg/articlelookup/doi/10.1093/bfgp/elq001>.

JUNG, M. S.; VIEIRA, E. A.; BRANCKER, A.; NODARI, R. O. Capacidade geral e específica de combinação de caracteres do fruto do maracujazeiro-doce (Passiflora alata Curtis). Ciência Rural, Santa Maria, v. 37, n. 4, p. 963-969, 2007a. 
JUNG, M. S.; VIEIRA, E. A.; BRANCKER, A.; NODARI, R. O. Herdabilidade e ganho genético em caracteres do fruto do maracujazeiro-doce. Rev. Bras. Frutic, v. 30, n. 1, p. 209-214, 2008.

JUNG, M. S.; VIEIRA, E. A.; DA SILVA, G. O.; BRANCKER, A.; NODARI, R. O. Capacidade de combinação por meio de análise multivariada para caracteres fenotípicos em maracujazeiro-doce. Pesquisa Agropecuaria Brasileira, v. 42, n. 5, p. 689-694, 2007b.

KAVATI, R.; PIZA JUNIOR, C. de T. Cultura do Maracujá-doce. $1^{\text {a }}$ ed. Campinas: CATI, 2002.

KUMAR, S.; CHAGNÉ, D.; BINK, M. C. A. M.; VOLZ, R. K.; WHITWORTH, C.; CARLISLE, C. Genomic selection for fruit quality traits in apple (Malus $\times$ domestica Borkh.). PLoS ONE, v. 7, n. 5, p. 1-10, 2012.

LAPERUTA, L. D. C. Estudo de uma população segregante (F1) de maracujá-doce: enriquecimento do mapa de ligação e mapeamento de QTL para produção e qualidade de frutos. 2011. Universidade de São Paulo Escola Superior de Agricultura "Luiz de Queiroz" Estudo, 2011.

MARTINS, M. R.; OlIVEIRA, J. C. De; DI MAURO, A. O.; SILVA, P. C. Da. Avaliação de populações de maracujazeiro-doce (Passiflora alata Curtis) obtidas de polinização aberta. Revista Brasileira de Fruticultura, v. 25, n. 1, p. 111-114, 2003.

MELETTI, L. M. M.; SANTOS, R. R. dos; MINAMI, K. Melhoramento do maracujazeiroamarelo: obtenção do cultivar "COMPOSTO IAC-27”. Scientia Agricola, v. 57, n. 3, p. 491-498, 2000. Disponível em: $<$ http:/ /www.scielo.br/scielo.php?script=sci_arttext\&pid=S010390162000000300019\&lng=pt\&tlng=pt $>$.

MOOSE, S. P.; MUMM, R. H. Molecular Plant Breeding as the Foundation for 21st Century Crop Improvement. Plant Physiology, v. 147, n. 3, p. 969-977, 2008. Disponível em: <http://www.plantphysiol.org/cgi/doi/10.1104/pp.108.118232>.

MORAES, M. C.; GERALDI, I. O.; DE PINA MATTA, F.; CARNEIRO, M. L. V. Genetic and phenotypic parameter estimates for yield and fruit quality traits from a single wide cross in yellow passion fruit. HortScience, v. 40, n. 7, p. 1978-1981, 2005.

NUNES, E. S. Caracterização fenotípica e molecular de uma população $\mathrm{F} 1$ de maracujádoce visando à construção de mapas de ligação e identificação de QTL. 2010. 138 p. 
Tese (Doutor em Ciências). Universidade de São Paulo Escola Superior de Agricultura "Luiz de Queiroz" Caracterização, 2010.

OLIVEIRA, E. J.; DA SILVA SANTOS, V.; SOUZA DE LIMA, D.; MACHADO, M. D.; LUCENA, R. S.; MOTTA, T. B. N.; DA SILVA CASTELLEN, M. Selection on yellow passion fruit progenies by multivariate indices Abstract. Pesquisa Agropecuaria Brasileira, v. 43, n. 11, p. 1543-1549, 2008.

OLIVEIRA, E. J.; SANTOS, V. da S.; LIMA, D. S.; MACHADO, M. D.; LUCENA, R. S.; MOTTA, T. B. N. Genotypic and phenotypic correlation estimates from passion fruit germplasm Abstract. Bragantia, Campinas, v. 70, n. 2, p. 255-261, 2011.

PASSAM, H. C.; KARAPANOS, I. C.; ALEXOPOULOS, A. a. The Biological Basis of Fruit Quality CO. Breeding for Fruit Quality, p. 5-38, 2011. Disponível em: <http://dx.doi.org/10.1002/9780470959350.ch1>.

PATTERSON, H.; THOMPSON, R. Recovery of inter-block information when block sizes are unequal. Biometrika, v. 58, 1971.

PEREIRA, G. da S.; LAPERUTA, L. D. C.; NUNES, E. S.; CHAVARRÍA, L.; PASTINA, M. M.; GAZAFFI, R.; GERALDI, I. O.; GARCIA, A. A. F.; CARNEIRO VIEIRA, M. L. The Sweet Passion Fruit (Passiflora alata) Crop: Genetic and Phenotypic Parameter Estimates and QTL Mapping for Fruit Traits. Tropical Plant Biology, v. 10, n. 1, p. 18-29, 2016.

PEREIRA, G. S.; NUNES, E. S.; LAPERUTA, L. D. C.; BRAGA, M. F.; PENHA, H. A.; DINIZ, A. L.; MUNHOZ, C. F.; GAZAFFI, R.; GARCIA, A. A. F.; VIEIRA, M. L. C. Molecular polymorphism and linkage analysis in sweet passion fruit, an outcrossing species. Annals of Applied Biology, v. 162, n. 3, p. 347-361, 2013.

PIEPHO, H. P.; MÖHRING, J. Computing heritability and selection response from unbalanced plant breeding trials. Genetics, v. 177, n. 3, p. 1881-1888, 2007.

PIEPHO, H. P.; MÖHRING, J.; MELCHINGER, A. E.; BÜCHSE, A. BLUP for phenotypic selection in plant breeding and variety testing. Euphytica, v. 161, n. 1-2, p. 209-228, 2008.

PINHEIRO, C. R. Mapeamento de QTL ( Quantitative Trait Loci ) associados à resposta do maracujá-doce à bacteriose usando a abordagem de modelos mistos. 2015. 122 p. Tese (Doutor em Ciência). Universidade de São Paulo Escola Superior de Agricultura "Luiz de Queiroz”. 2015.

RASCHER, U.; BLOSSFELD, S.; FIORANI, F.; JAHNKE, S.; JANSEN, M.; KUHN, A. J.; MATSUBARA, S.; MRTIN, L. L. A.; MERCHANT, A.; METZNER, R.; MLLER-LINOW, 
M.; NAGEL, K. A.; PIERUSCHKA, R.; PINTO, F.; SCHREIBER, C. M.; TEMPERTON, V. M.; THORPE, M. R.; VAN DUSSCHOTEN, D.; VAN VOLKENBURGH, E.; WINDT, C. W.; SCHURR, U. Non-invasive approaches for phenotyping of enhanced performance traits in bean. Functional Plant Biology, v. 38, n. 12, p. 968-983, 2011.

ROGÉRIO, L. D. O.; VON PINHO, R. G.; FERREIRA, D. F.; PIRES, L. P. M.; MELO, W.

M. C. Selection index in the study of adaptability and stability in maize. The Scientific World Journal, v. 2014, 2014.

SANTOS, F. S.; JÚNIOR, A. T. D. A.; JÚNIOR, S. D. P. F.; RANGEL, R. M.; PEREIRA, M.

G. Predição de ganhos genéticos na população de milho pipoca UNB-2U sob seleção recorrente utilizando-se diferentes índices de seleção. Semina:Ciencias Agrarias, v. 66, n. 3, p. 389-396, 2007.

SCHWARZ, G. Estimating the dimension of a model. The Annals of Statistics, v. 6, n. 2, p. 461-464, 1978. Disponível em: <http://projecteuclid.org/euclid.aos/1176344136>.

SILVA, F. H. de L. e; VIANA, A. P.; FREITAS, J. C. D. O.; SANTOS, E. A.; RODRIGUES, D. L.; AMARAL JUNIOR, A. T. do. Prediction of genetic gains by selection indexes and REML/BLUP methodology in a population of sour passion fruit under recurrent selection. Acta Scientiarum. Agronomy, v. 39, n. 2, p. 183, 2017. Disponível em: <http://periodicos.uem.br/ojs/index.php/ActaSciAgron/article/view/32554>.

SIQUEIRA, K. M. M.; KIILL, L. H. P. Informações Sobre Polinizadores em Maracujazeiro no Vale do São Francisco. Petrolina: Embrapa Semi-Árido. 24 p, 2009.

SMITH, A. B.; CULLIS, B. R.; THOMPSON, R. The analysis of crop cultivar breeding and evaluation trials: An overview of current mixed model approaches. Journal of Agricultural Science, v. 143, n. 6, p. 449-462, 2005.

SMITH, A. B.; GANESALINGAM, A.; KUCHEL, H.; CULLIS, B. R. Factor analytic mixed models for the provision of grower information from national crop variety testing programs. Theoretical and applied genetics., v. 128, n. 1, p. 55-72, 2015.

VIANA, A. P.; DE LIMA E SILVA, F. H.; GLÓRIA, L. S.; RIBEIRO, R. M.; KRAUSE, W.; BOECHAT, M. S. B. Implementing genomic selection in sour passion fruit population. Euphytica, v. 213, n. 10, p. 228, 2017. Disponível em: <http://link.springer.com/10.1007/s10681-017-2020-3>.

VIANA, A. P.; RESENDE, M. D. V. de. Genética Quantitativa no Melhoramento de Fruteiras. 1. ed. Rio de Janeiro, Brasil: Editora INTERCIÊNCIA, 2014. 
VIANA, J. M. S.; DE ALMEIDA, Í. F.; DE RESENDE, M. D. V.; FARIA, V. R.; E SILVA, F. F. BLUP for genetic evaluation of plants in non-inbred families of annual crops. Euphytica, v. 174, n. 1, p. 31-39, 2010.

YAN, W.; HUNT, L. a.; SHENG, Q.; SZLAVNICS, Z. Cultivar Evaluation and MegaEnvironment Investigation Based on the GGE Biplot. Crop Science, v. 40, n. 3, p. 597, 2000. 